\title{
Roseovarius sp. strain 217: aerobic taurine dissimilation via acetate kinase and acetate-CoA ligase
}

\author{
Marijke I. Baldock, Karin Denger, Theo H.M. Smits \& Alasdair M. Cook \\ Department of Biological Sciences, University of Konstanz, Konstanz, Germany
}

Correspondence: Alasdair M. Cook, Department of Biological Sciences, University of Konstanz, D-78457 Konstanz, Germany. Tel.: +497531 884247; fax: +497531 882966; e-mail: alasdair.cook@ uni-konstanz.de

\begin{abstract}
The genome sequence of Roseovarius sp. strain 217 indicated that many pathway enzymes found in other organisms for the degradation of taurine are represented, but that a novel, apparently energy-dependent pathway is involved in the conversion of acetyl phosphate to acetyl CoA. Thus, an ABC transporter for taurine could be postulated, while inducible taurine: pyruvate aminotransferase, alanine dehydrogenase, sulfoacetaldehyde acetyltransferase and sulfite dehydrogenase could be assayed. Whereas phosphate acetyltransferase has been found in other organisms, none was indicated in the genome sequence and no activity was found in cell-free extracts. Instead, acetate kinase was active as was acetate-CoA ligase.
\end{abstract}

Keywords

acetate:CoA ligase (AMP-forming); acetate kinase; Burkholderia xenovorans LB400;

genome sequences; Roseovarius sp. strain 217; taurine dissimilation.

\section{Introduction}

The first two research groups to work on the biochemistry of taurine dissimilation found evidence for different pathways leading to the desulfonation of sulfoacetaldehyde (Kondo et al., 1973; Shimamoto \& Berk, 1979). It has now been demonstrated that two uptake systems for taurine (ABC [TC 3.A.1.17.1] or TRAP [TC 2.A.56.4.1] transporters), two deamination systems (taurine dehydrogenase [EC 1.4.2.-] or the combination of taurine:pyruvate aminotransferase (Tpa) [EC 2.6.1.77] and alanine dehydrogenase (Ald) [EC 1.4.1.1]) and three subgroups of the desulfonative sulfoacetaldaldehyde acetyltransferase (Xsc) [EC 2.3.3.15] are widespread and can be found in different combinations in different organisms (Ruff et al., 2003; Brüggemann et al., 2004; Denger et al., 2006; Gorzynska et al., 2006). The excess ammonium ion from the deamination reaction is believed to be exported by the ammonium-methylammonium transporter AmtB (Gorzynska et al., 2006). The fate of the sulfite released in aerobic bacteria by Xsc seems to involve different sulfite dehydrogenases (e.g. SorAB) ([EC 1.8.2.1]), presumably intracellular or periplasmic, with correspondingly different sulfate (TauZ) [TC 9.B.63.1.1] or sulfite exporters (OrfX) (Rein et al., 2005; Denger et al., 2006; Cook et al., 2007). The fate of the acetyl phosphate produced by Xsc in aerobes has always involved phosphate acetyltransferase (Pta) [EC 2.3.1.8] to yield acetyl-CoA (Ruff et al., 2003; Brüggemann et al., 2004; Denger et al., 2006; Gorzynska et al., 2006), but the unfinished genome sequence of Roseovarius sp. strain 217 (Schäfer et al., 2005) indicated an alternative pathway.

Initial hypothesis of this study with these sequence data (Fig. 1a) involved an inducible ABC transporter (TauABC), the involvement of Tpa, Ald and an Xsc of subgroup 3, whereby the fate of both the sulfite and the acetyl phosphate was unclear. The presence of an acetate kinase gene (ack) directly downstream of $x s c$ then led to the prediction that taurine served as a sole source of nitrogen for growth and that the carbon atoms from taurine would be excreted as acetate. This would be a novel variant of established excretion of a carbon moiety from taurine (Denger et al., 2004b; Styp von Rekowski et al., 2005; Weinitschke et al., 2005). However, when Schäfer and Murrell supplied the organism, they informed us that taurine was a good carbon source. An unknown (or unsequenced) Pta or an alternative activation pathway to yield acetyl-CoA from the acetate generated by Ack was thus required, with which the organism could supply carbon for fatty acid synthesis, the Krebs cycle and the alternative glyoxylate shunt (see Alber et al., 2006). 
(a)

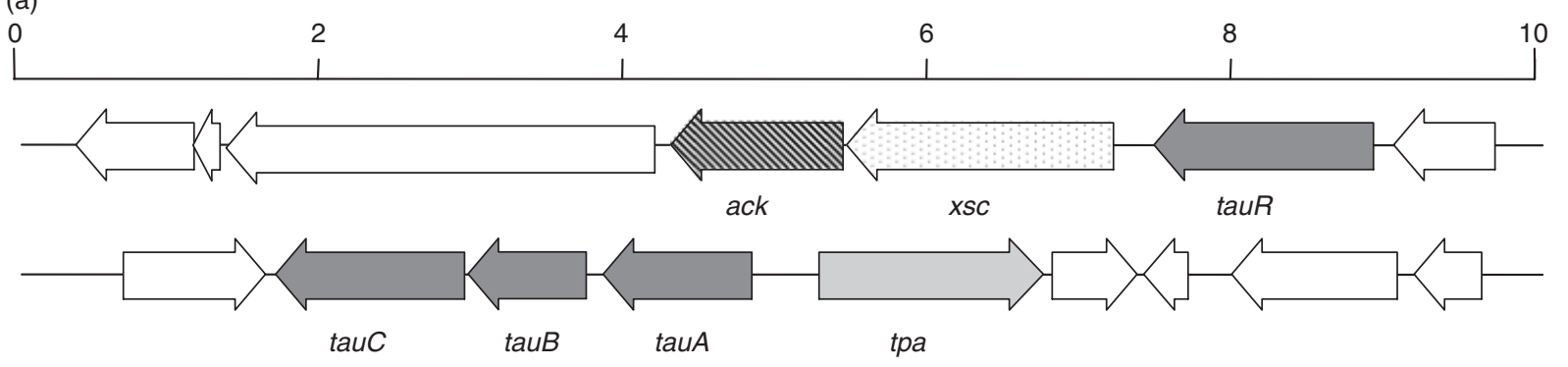

(b) Taurine

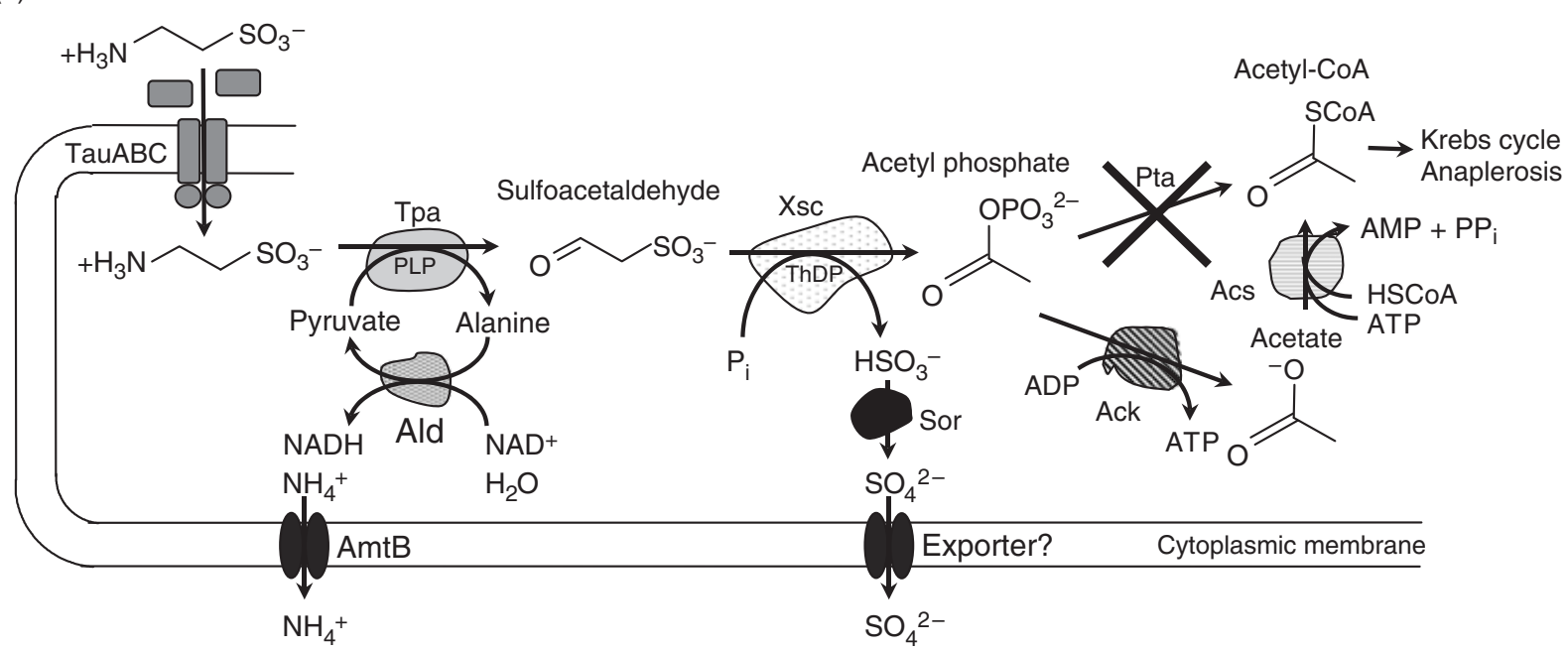

Fig. 1. Gene organization (a) and the corresponding pathway (b) deduced for the dissimilation of taurine in Roseovarius sp. strain 217. The gene loci are: tauR-ack, ROS217_11941 - ROS217_11831; tpa-tauABC, ROS217_11286 - ROS217_11271. An Amt-protein (e.g. ROS217_04110) is presumed to be expressed; the Ald-locus is ROS217_10232; the Acs-locus is presumably ROS217_16070. The nature of the Sor and the sulfate exporter are unknown. PLP, pyridoxal 5'-phosphate; ThDP, thiamin diphosphate.

Wolfe (2005) recently reviewed the reactions involved in the generation and activation of acetate. Data are now reported to confirm the initial reactions in taurine dissimilation and to identify Ack [EC 2.7.2.1] and acetate-CoA ligase (Acs) [EC 6.2.1.1] operating at the end of the pathway.

\section{Materials and methods}

\section{Organisms, growth media and growth}

Roseovarius sp. strain 217 was isolated by Schäfer et al.(2005) from the marine environment for its ability to utilize methyl halides, and sequence data of the unfinished genome (whole genome shotgun sequencing project NZ_AAMV00000000) were made available by the Moore Foundation (http:// www.moore.org/microgenome/). The completed genome sequence (GenBank accession numbers CP000270/ CP000271/CP000272) of Burkholderia xenovorans LB400 was made available by the US DOE Joint Genomic Institute (http://genome.jgi-psf.org/mic-home.html). Roseovarius sp. strain 217 was grown aerobically at $30^{\circ} \mathrm{C}$ in a modified basal medium (Baumann \& Baumann, 1981) containing halfstrength Artificial Sea Water (MacLeod \& Hori, 1960), in which the magnesium sulfate concentration was lowered to $1 \mathrm{mM}$ while the concentration of magnesium ion was maintained by adding the chloride salt. As the sole source of carbon and energy for growth, $10 \mathrm{mM}$ taurine, DL-malate or acetate was used. Alternatively, ammonium chloride was eliminated from the basal medium, and $2 \mathrm{mM}$ taurine was added as the sole source of nitrogen in presence of $10 \mathrm{mM}$ malate. Burkholderia xenovorans LB400 was grown as described previously (Ruff et al., 2003).

Growth was followed in $50-\mathrm{mL}$ cultures in $300-\mathrm{mL}$ Erlenmeyer flasks on a rotary shaker. Samples were taken at intervals to measure turbidity at $580 \mathrm{~nm}$, to assay protein and to determine the concentrations of sulfate, taurine, acetate and the ammonium ion. When larger amounts of cells were required for crude extracts, $200 \mathrm{~mL}$ cultures, with $10 \mathrm{mM}$ taurine, acetate or malate, in $1 \mathrm{~L}$ Erlenmeyer flasks were used. 


\section{Analytical methods}

Taurine was quantified by HPLC after derivatization with 2,4-dinitrofluorobenzene (Denger et al., 1997). Acetate was determined by GC (Laue et al., 1997). Sulfate was measured as a suspension of $\mathrm{BaSO}_{4}$ (Sörbo, 1987). Protein in whole cells was assayed in a Lowry-type reaction (Cook \& Hütter, 1981); protein in crude extract was assayed by dye-binding (Bradford, 1976). The ammonium ion was determined enzymically (Bergmeyer \& Beutler, 1984).

\section{Enzyme assays}

Tpa was assayed discontinuously by following taurine disappearance and alanine formation (Denger et al., 2004a). Ald was assayed photometrically at $365 \mathrm{~nm}$ (Denger et al., 2004a). Xsc or Ack was assayed discontinuously in a spectrophotometer as the formation of the iron complex of acetylhydroxamate (Rose, 1955; Ruff et al., 2003). Pta was assayed photometrically as the formation of acetyl-CoA (Bergmeyer et al., 1983). Sulfite dehydrogenase (Sor) was assayed photometrically as the oxidation of ferricyanide (Reichenbecher et al., 1999). Acs was assayed discontinuously using HPLC analysis to quantify reaction products. The reaction mixture contained $50 \mathrm{mM}$ triethanolamine buffer, pH 8.0 (containing $2.5 \mathrm{mM} \mathrm{MgCl}_{2}$ ), $0.2 \mathrm{mM}$ ATP, $0.2 \mathrm{mM}$ CoA, $10 \mathrm{mM}$ acetate and c. $0.25 \mathrm{mg}$ protein. Samples of $500 \mu \mathrm{L}$ were taken at intervals and added to $500 \mu \mathrm{L}$ methanol, to stop the reaction. The formation of acetyl CoA and AMP and the decrease of ATP and CoA were followed by HPLC: the mobile phase was $50 \mathrm{mM}$ potassium phosphate buffer, $\mathrm{pH} 2.2$, and a linear gradient of methanol to $30 \%$ was applied.

\section{Results and discussion}

\section{Quantitative aspects of growth}

Roseovarius sp. strain 217 grew exponentially with taurine as the sole source of carbon and energy (Fig. 2a); the growth rate $(\mu)$ was $0.045 \mathrm{~h}^{-1}$ (representative of three experiments). The utilization of taurine was concomitant with growth (Fig. 2b) and the molar growth yield (6.5 g protein mol $\mathrm{C}^{-1}$ ) was in the range consistent with quantitative utilization of the substrate (Cook \& Hütter, 1981): no release of acetate was detected (Fig. 2b). The specific utilization rate of taurine was calculated from these data to be $3.8 \mathrm{mkat} \mathrm{kg}^{-1}$ of protein. A net release of about $9 \mathrm{mM} \mathrm{NH}_{4}^{+}$from about $12 \mathrm{mM}$ taurine was observed (Fig. 2b); the balance of the nitrogen was calculated to be in cell polymers. The formation of about $10 \mathrm{mM} \mathrm{SO}_{4}^{2-}$ was found (Fig. 2b), which was presumed to represent quantitative release of sulfate from the sulfonate moiety. There was, thus, mass balance for the
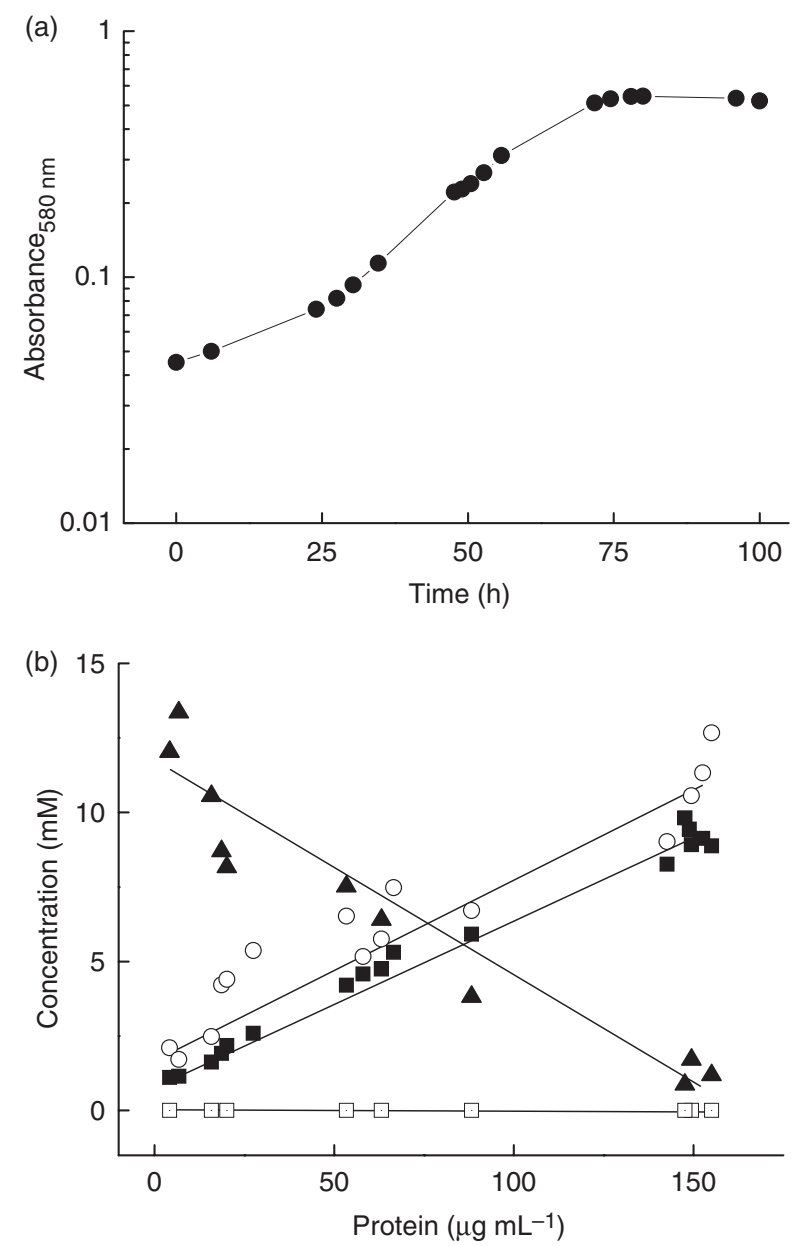

Fig. 2. Kinetics of growth with taurine of Roseovarius sp. strain 217 (a), and substrate utilization and product formation as a function of growth (b). $\bullet$, turbidity; $\boldsymbol{\Delta}$, taurine; $\mathbf{\square}$, sulfate; o, ammonium ion; $\square$, acetate.

carbon, nitrogen and sulfur moieties during the catabolism of taurine.

Taurine could serve as a sole source of nitrogen for the growth of Roseovarius sp. strain 217 with malate as the source of added carbon (not shown). There was no excretion of acetate under those conditions, either.

Roseovarius sp. strain 217 was tested for growth with different aliphatic sulfonates and was shown to grow well with isethionate, cysteate, sulfolactate, $N$-methyltaurine and $\mathrm{N}$-acetyltaurine as sole sources of carbon and energy. In all cases, sulfate was detected in the medium, indicating substrate utilization. The organism did not grow with methanesulfonate (Schäfer et al., 2005), sulfoacetate, sulfopropane or 1,3-disulfopropane.

\section{Enzyme activities}

Roseovarius sp. strain 217 could be grown in gram-amounts and crude cell extracts were generated. Extracts of malate- 
Table 1. Specific activities of enzymes relevant to taurine dissimilation in extracts of induced and noninduced cells of Roseovarius sp. strain 217

\begin{tabular}{llc}
\hline & $\begin{array}{l}\text { Specific activity } \\
\text { (mkat kg }\end{array}$ \\
& $\begin{array}{l}\text { in extracts of cells } \\
\text { grown with }\end{array}$ \\
\cline { 2 - 3 } Enzyme & Malate & Taurine \\
\hline Taurine:pyruvate aminotransferase (Tpa) & $\mathrm{ND}$ & 1.9 \\
Alanine dehydrogenase (Ald) & 0.4 & 10 \\
Sulfoacetaldehyde acetyltransferase (Xsc) & $\mathrm{ND}$ & 3.8 \\
Sulfite dehydrogenase (Sor) & 0.3 & 5.3 \\
Phosphate acetyltransferase (Pta) & $\mathrm{ND}$ & $\mathrm{ND}$ \\
Acetate kinase (Ack) & 0.2 & 9.4 \\
Acetate-CoA ligase (Acs) & 0.07 & 0.8 \\
\hline
\end{tabular}

ND, not detected.

grown cells contained negligible levels of enzyme activities, which are directly involved in sulfonate metabolism (Table 1). In contrast, extracts of taurine-grown cells contained the predicted activities of Tpa, Ald, and Xsc, as well as Sor (Table 1). These data are interpreted to confirm the induction of the enzymes of the degradative pathway for taurine, including the $\mathrm{ABC}$ transporter (TauABC; Fig. 1), for which no direct evidence is available. The frequent occurrence of the tauR-gene in a cluster involving a taurine pathway (Brüggemann et al., 2004; Denger et al., 2004a, b, 2006; Gorzynska et al., 2006; T.H.M. Smits, unpublished) leads us to postulate that TauR is the transcriptional regulator for expression of the taurine genes. TauR is a MocR-type regulator in the GntR-family, and the conservation level within this large group is $\geq 40 \%$.

No activity of phosphate acetyltransferase was found (Table 1), in contrast to work in other organisms (Ruff et al., 2003; Brüggemann et al., 2004; Denger et al., 2006; Gorzynska et al., 2006). However, as predicted from the partial genome sequence (Fig. 1), inducible acetate kinase (Ack) was detected in significant amounts (Table 1) relative to the specific turnover rate of taurine $\left(3.8 \mathrm{mkatkg}^{-1}\right.$ protein, above). Correspondingly, 11-fold induction of the activity of Acs was detected (Table 1). The reaction was followed by HPLC, where the formation of acetyl CoA was confirmed by cochromatography with authentic material (not shown). Similarly, the formation of AMP from ATP was detected. The activity was apparently that of EC 6.2.1.1 [acetate:CoA ligase (AMP-forming)].

It was of concern that the assay of Pta might be inadequate, so another organism was used as a positive control. Inducible Pta was found in B. xenovorans LB400, which was previously shown to utilize taurine (Ruff et al., 2003). No Ack was formed under these conditions, though Acs (0.6 $\mathrm{mkat} \mathrm{kg}^{-1}$ protein) was observed (not shown).
Roseovarius sp. strain 217 is the first aerobic organism to be shown to contain an alternative pathway to the Pta observed previously (cf. Cook \& Denger, 2002; Denger et al., 2006; Gorzynska et al., 2006), but recent data from genome sequencing indicate other aerobes with a similar pathway. Roseobacter sp. strain MED193 contains a cluster containing tauR, $x s c$, a gene encoding a DUF81 protein (DUF, domain of unknown function), ack and tauZ but no pta gene; given candidate tpa- and acs-genes, a pathway similar to that in Fig. 1b, but with a known sulfate exporter (TauZ) (Rein et al., 2005; Denger et al., 2006), is presumed to be present. Similarly, in Dinoroseobacter shibae DFL 12, one of the three $x s c$-paralogues is flanked by tauR- and ackgenes.

\section{Conclusions}

Roseovarius sp. strain 217 is able to generate acetyl CoA from acetyl phosphate, but instead of the energetically neutral reaction of Pta, a two-step sequence is used in which the high-energy phosphate bond from acetyl phosphate is conserved as ATP in Ack, but two high-energy bonds are expended in Acs. This alternative route to generate acetyl CoA for biosynthesis of fatty acids, for entry into the tricarboxylic acid cycle and into the newly found alternative glyoxylate anaplerotic pathway (Alber et al., 2006), is apparently not limited to Roseovarius sp. strain 217 , because a similar set of genes is found in two other organisms in the Roseobacter clade. There would appear to be very considerable diversity in the pathways of taurine dissimilation, which suggests that the substrate must be widespread in many ecosystems.

\section{Acknowledgements}

T. Döderlein, who generated a significant portion of the data in a practical for advanced undergraduates, is thanked. H. Schäfer and J.C. Murrell (Roseovarius sp. strain 217), and J. Tiedje (B. xenovorans LB400), kindly made organisms available. The research was funded by the University of Konstanz.

\section{References}

Alber BE, Spanheimer R, Ebenau-Jehle C \& Fuchs G. (2006) Study of an alternative glyoxylate cycle for acetate assimilation by Rhodobacter sphaeroides. Mol Microbiol 61: 297-309.

Baumann P \& Baumann L (1981) The marine Gram-negative eubacteria: Genera Photobacterium, Beneckea, Alteromonas, Pseudomonas and Alcaligenes. The Prokaryotes (Starr MP, Stolp H, Trüper HG, Balows A \& Schlegel H-G, eds), pp. 1302-1331. Springer Verlag, Berlin. 
Bergmeyer HU \& Beutler H-O (1984) Ammonia. Methods of Enzymic Analysis, 3rd edn (Bergmeyer HU, ed.), pp. 454-461. Verlag Chemie, Weinheim.

Bergmeyer HU, Graßl M \& Walter E-M (1983)

Phosphotransacetylase. Methods of Enzymatic Analysis, 3rd edn (Bergmeyer HU, ed.), pp. 295-296. Verlag Chemie, Weinheim. Bradford M (1976) A rapid and sensitive method for the quantitation of microgram quantities of protein utilizing the principle of protein-dye binding. Anal Biochem 72: 248-254.

Brüggemann C, Denger K, Cook AM \& Ruff J (2004) Enzymes and genes of taurine and isethionate dissimilation in Paracoccus denitrificans. Microbiology (Reading, UK) 150: 805-816.

Cook AM \& Denger K (2002) Dissimilation of the $\mathrm{C}_{2}$ sulfonates. Arch Microbiol 179: 1-6.

Cook AM \& Hütter R (1981) S-Triazines as nitrogen sources for bacteria. J Agric Food Chem 29: 1135-1143.

Cook AM, Smits THM \& Denger K (2007) Sulfonates and organotrophic sulfite metabolism. (Friedrich CG \& Dahl C, eds), Microbial Sulfur Metabolism, Springer Verlag, New York, in press.

Denger K, Laue H \& Cook AM (1997) Anaerobic taurine oxidation: a novel reaction by a nitrate-reducing Alcaligenes sp. Microbiology (Reading, UK) 143: 1919-1924.

Denger K, Ruff J, Schleheck D \& Cook AM (2004a) Rhodococcus opacus expresses the xsc gene to utilize taurine as a carbon source or as a nitrogen source but not as a sulfur source. Microbiology (Reading, UK) 150: 1859-1867.

Denger K, Weinitschke S, Hollemeyer K \& Cook AM (2004b) Sulfoacetate generated by Rhodopseudomonas palustris from taurine. Arch Microbiol 182: 254-258.

Denger K., Smits THM \& Cook AM. (2006) Genome-enabled analysis of the utilization of taurine as sole source of carbon or nitrogen by Rhodobacter sphaeroides 2.4.1. Microbiology (Reading, UK) 152: 3167-3174.

Gorzynska AK, Denger K, Cook AM \& Smits THM (2006) Inducible transcription of genes involved in taurine uptake and dissimilation by Silicibacter pomeroyi DSS- $3^{\mathrm{T}}$. Arch Microbiol 185: 402-606.
Kondo H, Kagotani K, Oshima M \& Ishimoto M (1973) Purification and some properties of taurine dehydrogenase from a bacterium. J Biochem 73: 1269-1278.

Laue H, Denger K \& Cook AM (1997) Taurine reduction in anaerobic respiration of Bilophila wadsworthia RZATAU. Appl Environ Microbiol 63: 2016-2021.

MacLeod RA. \& Hori A. (1960) Nutrition and metabolism of marine bacteria VIII: tricarboxylic acid cycle enzymes in a marine bacterium and their response to inorganic salts. J Bacteriol 80: 464-471.

Reichenbecher W, Kelly DP \& Murrell JC (1999) Desulfonation of propanesulfonic acid by Comamonas acidovorans strain P53: evidence for an alkanesulfonate sulfonatase and an atypical sulfite dehydrogenase. Arch Microbiol 172: 387-392.

Rein U, Gueta R, Denger K, Ruff J, Hollemeyer K \& Cook AM (2005) Dissimilation of cysteate via 3-sulfolactate sulfo-lyase and a sulfate exporter in Paracoccus pantotrophus NKNCYSA. Microbiology (Reading, UK) 151: 737-747.

Rose IA (1955) Acetate kinase of bacteria (acetokinase). Methods Enzymol 3: 591-595.

Ruff J, Denger K \& Cook AM (2003) Sulphoacetaldehyde acetyltransferase yields acetyl phosphate: purification from Alcaligenes defragrans and gene clusters in taurine degradation. Biochem J 369: 275-285.

Schäfer H, McDonald IR, Nightingale PD \& Murrell JC (2005) Evidence for the presence of a CmuA methyltransferase pathway in novel marine methyl halide-oxidizing bacteria. Environ Microbiol 7: 839-852.

Shimamoto G \& Berk RS (1979) Catabolism of taurine in Pseudomonas aeruginosa. Biochim Biophys Acta 569: 287-292.

Sörbo B (1987) Sulfate: turbidimetric and nephelometric methods. Methods Enzymol 143: 3-6.

Styp von Rekowski K, Denger K \& Cook AM (2005) Isethionate as a product from taurine during nitrogen-limited growth of Klebsiella oxytoca Tau-N1. Arch Microbiol 183: 325-330.

Weinitschke S, Styp von Rekowski K, Denger K \& Cook AM (2005) Sulfoacetaldehyde is excreted quantitatively by Acinetobacter calcoaceticus SW1 during growth with taurine as sole source of nitrogen. Microbiology (Reading, UK) 151: 1285-1290.

Wolfe AJ (2005) The acetate switch. Microbiol Mol Biol Rev 69: 12-50. 